\title{
LA CULTURA CASTREÑA EN GAIICIA: HISTORIOGRAFIA ARQUEOLÓGICA DE LOS ÚLTIMOS AÑOS (1980-1996)
}

\author{
VÍCTOR ALONSO \\ Universidad de La Coruña
}

\section{Resumen}

El objetivo de este trabajo es ofrecer un panorama general de los estudios recientes sobre arqueologia castreña de Galicia, presentando los avances de la investigación y las novedades bibliográficas que afectan al ámbito geográfico galaico durante la Protohistoria.

\section{Summary}

This paper provides a general eveview of recent rescarch on the archaeslogy of Galicia ("cultura castreña") durig the pre-Roman and Early roman periods. Recent discoveries and publications involving the nothwestern regions of Spain are presented and discused in detail.

A casi un siglo de la muerte del portugués Martins Sarmento (1833-1899), excavador de Briteiros y Sabroso e investigador pionero de la protohistoria galaica (CARDOzO, 1985, 1996), puede decirse que bastantes cosas han cambiado en el panorama de los estudios castreños. No es que la labor excavadora de aquellos caballeros de la arqueología deba menospreciarse (los Sarmento, Vasconcelos, Maciñeira, Pericot, etc.), pues al fin y al cabo fueron ellos los grandes impulsores del trabajo de campo y de la conservación museística: quién no se admira aún hoy con el legado de la Sociedad Martins Sarmento de Guimarâes, o con los desvelos de la Comisión Provincial de Monumentos Históricos y Artísticos de Orense en tiempos de Marcelo Macías, o con la labor de la Sociedad Arqueológica de Pontevedra, dirigida a comienzos de siglo por Casto Sampedro. Es, por contra, en el delicado apartado de la interpretación histórica donde descu- 
brimos la inocencia de aquella edad decimonónica, schliemanniana o whartoniana, según se mire, en la cual se apelaba al aventurero micénico, al colonizador griego o al invasor celta casi con la misma candidez con la que otros estudiosos explicaban el origen de la civilización maya por la arribada de navegantes egipcios al nuevo mundo o, aún más recientemente, el megalitismo europeo por la irrupción de los famosos misioneros de una nueva religión originaria del Oriente. Excesos románticos y demás dislates difusionistas aparte, la verdad es que el proceso de civilización - dicho esto con el permiso de Colin Renfrew (1972)-, no excluye en modo alguno factores de activación exterior, antes bien, las recientes investigaciones sobre la protohistoria del NO peninsular abundan de manera convincente en la influencia transformadora de las corrientes indoeuropeas (atlánticas, quizá también hallstáticas) y mediterráneas (tartessio-semitas) sobre el rico sustrato del Bronce final (CALO, SIERRA, 1983; VAZZUEZ VARELA, 1993; ALMAGRO-GORBEA, 1995a; RulZ-GALVEZ, 1995; DE LA PENA, 1996, 70s; con variantes según los autores).

Quien se asome a los estudios castreños de los años ochenta y comienzos de los noventa se llevará una grata sorpresa ante el aumento en cantidad y calidad de las publicaciones, y ello hasta tal punto, que los comienzos de la nueva etapa autonómica quizá lleguen a ser evaluados en un futuro como los de una auténtica edad de renacimiento en la arqueología gallega, al menos en lo que se refiere a la investigación protohistórica (estados sucesivos de la cuestión: Acuña 1977; Fariña, Arias, Romero 1983; Martins 1988; Eiroa 1988). Tómese, para probarlo, como punto de referencia el balance de conocimientos presentado hace veinte años por Juan Maluquer (1975), y se comprobarán los avances con respecto a los límites señalados por el arqueólogo catalán. Protagonistas indiscutibles de este nuevo impulso están siéndolo el profesorado universitario (con Santiago de Compostela como alma mater), el personal directivo e investigador asociado a los activisimos museos gallegos (provinciales, municipales y locales) y al Instituo Padre Sarmiento, sin olvidar tampoco esos focos de estudio nunca extinguidos, afortunadamente, que se mantienen en algunos centros estatales de enseñanza media. En fin, si se tratase de mencionar algún nombre relevante por su magisterio, destacariamos aquí a dos catedráticos muy vinculados a la universidad compostelana, no ha mucho tiempo fallecidos: Carlos Alonso del Real y Alberto Balil Illana ${ }^{1}$.

La década prodigiosa de los ochenta, más aún que ésta de los noventa, vio magníficos progresos, así en el trabajo de campo, como en la sistematización y la divulgación

${ }^{1}$ Aunque los trabajos de los colegas portugueses serán también citados, porque su aportación desde Martins Sarmento y Leite de Vasconcelos resulta absolutamente insoslayable (los Serpa Pinto, Cardozo, Ferreira de Almeida, Brochado, Da Silva, Sampaio, Encarnaçâo, Martins, etc.), en este artículo nos centraremos en los avances de la investigación en Galicia. Síntesis portuguesas de la última época pueden ser las de DA SilVh, 1986, 1990, y FABIÁO, 1993. Para Asturias, MAYA, 1988, 1989; CARROCERA, 1990, 1994, 1996, asi como dos trabajos de F. JORDA, 1977, 1984; y LOMAS, 1975, y FERNÁNDEZ OCHOA, 1982. POr lo demás, introducimos en este artículo el término bistoriografía arqueológica a sabiendas de que la renovación epistemológica, esto es, metodológica y conceptual, desde los años sesenta, cuando menos desde la nueva arqueología, ha tenido como consecuencia la problematización y enriquecimiento del discurso interpretativo en esta disciplina, con toda la secuela de corrientes, escuelas y posiciones interdisciplinares, etc, que en definitiva han desembocado en la constitución de un verdadero acervo historiografico. 
científicas, y todo ello merced en buena medida al empeño financiero de la Xunta de Galicia, a cuya consejería de cultura se vinculan tres colecciones: Arqueoloxía / Memorias, Arqueolaxia /Investigación, y Arqueoloxia /Informes.

La primera serie recoge las memorias de excavación correspondientes a distintos castros localizados en las cuatro provincias gallegas, antes sólo prospectados, o sólo sondeados, o parcialmente excavados, o incluso en un caso pendiente de publicación. Son los yacimientos de Vigo (Hidalgo, 1985a), Viladonga en Lugo (ARIAS, 1985), Troña en Pontevedra (HIDAlGo, 1985b), Penalba en Pontevedra (ÁLVAREZ, 1986), Santa Tecla en Pontevedra (DE LA PEÑa, 1986), Baroña en Coruña (CALo, SOEIRo, 1986), Borneiro en Conuña (Romero, 1987), Da Fotca en Pontevedra (Carballo, 1987), Fozara en Pontevedra (Hidalgo, RODRígueZ, 1987), Coto do Mosteiro en Orense (ORERO, 1988), Torroso en Pontevedra (DE LA PEÑA, 1992), Cameixa en Orense (LOPEZ CUEVILLAS, LORENZO FERNÁNDEZ, 1986) y, fuera ya de esta serie, San Cibrán de Las en Orense (Pérez OuteiriNo, 1985) y O Barral en Coruna (REy, 1986). De no poder contar el lector con estos informes, puede hacerse una cierta idea de sus resultados en el resumen de los mismos ofrecido por Eiroa (1988). Pasando al apartado de monografias temáticas y territoriales, cabe destacar el estudio ejemplar, y parece que seminal, de Carballo (1986) sobre el poblamiento galaico-romano en la tierra de Trasdeza, así como el dirigido por Criado (1991), que gira en tomo a la arqueologia del paisaje en el área Bocelo-Furelos, desde el paleolítico superior hasta la época medieval, incluyendo un capítulo de poblados de la edad del hierro; también se recogen bajo el mismo rótulo bibliográfico las muestras de análisis paleobotánicos y edafológicos realizados por Aira, Saa y Taboada (1989) en distintos yacimientos gallegos - y buena cosa es la colaboración que se observa entre las áreas de prehistoria y arqueología y los institutos de ciencias naturales, como aún tendremos nueva ocasión de certificar-, asi como una catalogación de yacimientos prerromanos del término de Santiago (A.A.V.V. 1987b). En tercer lugar, en fin, han empezado a salir los informes anuales de las campañas arqueológicas financiadas por la Xunta dentro de la comunidad autónoma, si bien con una lentitud irritante, ya que hasta la fecha sólo contamos con los relativos a 1987, 1988 y 1989 (1990 lleva ya tiempo anunciado en prensa), relaciones de grandísima utilidad para hacerse una idea concreta sobre la marcha general del trabajo arqueológico en Galicia. Sería conveniente, en cualquier caso, que se retomase el ritmo de excavación de los ochenta, aquella década prodigiosa de la arqueología gallega, y sobre todo que no se diese exclusiva prioridad a la llamada arqueología de gestión (ACUÑa, 1996, 36-37; DE LA PEÑA, 1996, 66).

El último sexenio de los noventa ofrece una imagen bastante precisa del incesante trabajo dado a los tôrculos gallegos por nuestros prehistoriadores y arqueólogos. No hay formato ni género que no haya sido cultivado por los estudiosos: del corpus de materiales al diccionario (CALO, 1994; ARIAS, ROMERO, 1995), de la monografia al manual (NAVEIRO, 1991; CALO, 1993), de la memoria de excavación a la guía y catalogación de materiales de yacimiento y/o de museo monográfico (MARTÍNEZ TAMUXE, 1995; RODRÍGUEZ, XUSTO, FARIÑA, 1993; CARBALLO, 1994; ARIAS, 1990, 1996; CASTAÑo, 1991; HidALGO, RODRÍGLEZ, DOMfNGUEZ, 1997) y al catálogo de exposición (AA.VV. 1991a/b, 1997), pasando por los inevitables informes arqueológicos de urgencia (numerosos artículos), las actas de congresos (22 CNA. Vigo 1993), los repertorios bibliográficos (AMADO, PEREIRO, 1991; SENin, 1995, este 
último para el paleolítico), los estudios de historiografía (ZARZALEJOS, 1991; CALO, 1993, 23s; ACUNA, 1996), los volúmenes de homenaje (AA.VV. 1993), las pequeñas historias locales (COSTAS y otros, 1996), e incluso el libro de gran divulgación ilustrado con técnicas de composición parecidas a las del cuento (Pena, Merlán, Filgueira 1995). No deben desdeñarse tampoco las distintas entradas que en la Gran Enciclopedia Gallega abordan la temática que nos ocupa, con voces tales como $<<$ arqueología $>>,<<$ castros $>>,<<$ celtas $>>,<<c u l u-$ ra castrexa $>>,<<$ orfebrería prerromana $>>,<<$ torques $>>,<<$ fibulas $>>$, etc., siempre a cargo de primeros especialistas (Romero, Acuña, Blanco, Pérez Outeiriño, Fariña). A todo ello, en fin, hemos de sumar la continuidad y aumento de publicaciones periódicas, más o menos especializadas, que dan cuenta de los avances en nuestro conocimiento ${ }^{2}$.

Dicho todo lo cual, y evitando caer en triunfalismos, podriamos tomar la leyenda del quinto centenario de la universidad compostelana (curso 1995/96) y decir nosotros que en la historiografia arqueológica Gallaecia fulget, sí, pero también que hay que seguir excavando...

Quizá fueron las Actas del XXII Congreso Nacional de Arqueologia (1995), celebrado en Vigo en 1993, el mejor exponente del reconocimiento otorgado a la arqueologia gallega de los últimos tiempos. A más de quince años del habido en Lugo, con ocasión del bimilenario (1976), y a ya cuarenta del reunido en Orense (1953), cuando vivía López Cuevillas, el congreso de la ciudad olívica tuvo por presidente a Fernando Acuna Castroviejo (Univ. Santiago) y por secretario ejecutivo a José Manuel Hidalgo Cuñarro (Museo Quiñones de León). En las actas se recogen 3 ponencias y 134 comunicaciones, de las que unas 77 interesan de manera directa al ámbito galaico, bien a su prehistoria, bien a su protohistoria castreña y êpoca romana (amén de las referidas a conservación y patrimonio, faceta cada día más atendida, y también cada día que pasa más preocupante). Por su visión panorámica y amplitud cronológica vale la pena mirar las ponencias de Ruíz-Gálvez y de Almagro-Gorbea, en especial la de este último por entrar de lleno en el estado del debate sobre la celtización peninsular y galaica -debate tan eterno como la entrada de los indoeuropeos en Grecia o la de los dorios-, proponiendo el autor una nueva hipótesis de trabajo "basada en la interpretación de un substrato cultural protocéltico del que paulatinamente habrian surgido los pueblos celtas de la Península Ibérica, en concreto, los celtiberos" (1995a, 130; y muy en consonancia con ello, EIROA, 1996). Por lo demás, y pese a que falte algún especialista de relieve, estas actas deben ser consultadas para cualquier trabajo que se emprenda: dan una idea bastante ajustada a la rea-

${ }^{2}$ Anuario Brigantino (Betanzos), Brigantium (La Coruña), Boletin Auriense (Orense), Boletin del Museo Arqueologito de Orense, Boletín do Museo Provincial de Lugo, Castrelos (Vigo), Cuadernos de Estudios Gallegos (Santiago), Gallaecia (Santiago), Larouco (Bande, Orense), El Museo de Pontevedra, Pontetedra Arqueologica, etc. 
lidad de las prospecciones, excavaciones y orientaciones temáticas y metodológicas de la arqueología gallega.

Una de las obras recientes que asimismo merece principal atención, y cuya adquisición por nuestras bibliotecas debiera ser obligada, es la de Francisco Calo Lourido (1994), un valioso corpus comentado de toda la plástica de la cultura castreña gallegoportuguesa, en dos volúmenes. Con muy buen criterio el autor ha prescindido para su confección de las actuales fronteras político-administrativas, del todo improcedentes en el estudio de un mundo que las superaba con amplitud: como mínimo, que alcanzaba desde la costa atlántica hasta las lineas marcadas por el Navia y por la divisoria del Támega y el Túa, y en dirección sur hasta el Duero. En este sentido, y para espantar hodiernos prejuicios, C.L. ofrece un estado de la cuestión sobre los límites espaciales y cronológicos de la cultura castreña (p. $43 \mathrm{~s}$ ), al que sigue ya la catalogación de las piezas sobre un total de 95 castros distintos, asi en Galícia como en el norte de Portugal: estatuas de guerreros, figuras sedentes, cabezas humanas, cabezas de animales, esculturas diversas, decoraciones arquitectónicas, y por último las llamadas <<pedras formosas > (todas las piezas acompanadas de fotografias y localizadas en los correspondientes mapas de distribución zonal). Se completa así, por lo que al mundo castreño se refiere, el corpus de alcance peninsular, pero ceñido únicamente a la escultura zoomorfa, elaborado por G.López Monteagudo (1989, a completar ahora con ÁlvAREZ-SANCHIS, 1995, por incidir en el ámbito galaico).

En general resulta bastante equilibrado el examen realizado por C.L. de las diversas manifestaciones de la plástica 《<castrexo-romana>> o <<galaico-romana〉>, como propone denominarla el autor (p. 786). Quizá en el análisis de la estatuaria sedente (la pieza de Lanhoso y la pareja de Ginzo), habida cuenta de la abundancia de paralelos iconográficos orientales y de sus rasgos claramente alóctonos, no debiéramos cerramos a ciertas hipótesis ya enunciadas de identificación teonímica sobre el trasfondo del panteón mediterráneo o incluso del sistema religioso conocido de los galaicos (RODRíguez COlMENERO, 1993, 446s). Exhaustivo por lo demás en los estados de la cuestión, hasta el punto de resumir a veces trabajos de escaso valor, su toma de posición contraria a una tradición escultórica prerromana con entidad precursora acaso parezca algo rotunda $\mathrm{y}$, de confirmarse, habría que hablar lisa y llanamente de estatuaria provincial de época romana (altoimperial), sin adjetivación castreña, pues en nada la merecería, ni en lo formal ni en lo conceptual (reafirmándose en ello CALO, 1997). Sucede que esta valoración de la escultura galaica, que no todos comparten en los mismos términos (por ej., TRANOY, 1988; VÁZQUeZ VARELA, 1993, 205; REY, 1996, 189s), desconecta a la plástica noroccidental del endogenismo cultural postulado hoy para lo castreño, desde el hábitat a la orfebrería, desde la cerámica al armamento y demás formas ergológicas, que se explica a partir del activo sustrato del Bronce final. En fin, por lo que se refiere a la función de las estatuas de guerreros, como asi se las ha venido denominando, tampoco parece tan claro que deba abandonarse en todos los casos la interpretación funeraria, máxime si tenemos en cuenta la descontextualización arqueológica de gran número de ellas: el coronamiento tumular con figura del difunto armado está atestiguada en la primitiva plástica germánica 
del periodo hallstático, también estílisticamente híbrida (bárbara y mediterránea), como demuestra una pieza del museo de Stuttgart que recomendamos ver (HATT, 1976, fig.1314; MENGHIN, 1980, 104-5). Sean cuales fueren las objeciones que este corpus suscite, como es normal en publicaciones omnicomprensivas y ambiciosas, nos parece en todo caso que en nada deben alterar la calificación meridianamente positiva que el mismo se merece.

Mayor tradición que la relativa a la plástica tiene la historiografia arqueológica tocante a la riquísima orfebrería castreña: torques, diademas, arracadas, brazaletes, anillos en espiral, collares articulados, y demás piezas de uso incierto (incluidas las enigmáticas lúnulas?). Una joyería que cuenta con claros y brillantes precedentes en el Bronce del NO, como atestigua el fabuloso tesoro de Caldas de Reyes, expuesto en el museo de Pontevedra (PINGEL, 1991). En este apartado siguen siendo trabajos de obligada consulta los de López Cuevillas (1951) y Blanco Freijeiro (1957), y más recientemente la monografia de Pérez Outeiriño sobre las arracadas (1982), así como los artículos de este último y Sánchez Palencia incluidos en el volumen aparte de la revista Arqueología dedicado al oro en la España prerromana (AA.VV. 1989). Recientemente han salido dos libros sobre la joyería galaica, a cargo de Castro (1990) y Balseiro (1995), de síntesis e inventario respectivamente, junto a los que cabría mencionar el estudio de iconografia comparada dedicado a la diadema (o cinturón) de Ribadeo (PARZINGER, 1991), sin olvidar análisis concretos, como el anunciado sobre el tesoro Bedoya (BALSEIRO, 1997) o sobre el polémico carnero alado también de Ribadeo, parece ahora que de época selyúcida, s. X-Xil d.C. (ENCINAS, CASTRO, 1995). No menos digna de tener en cuenta, por la cualificación de sus autores y las continuas referencias a orfebreria y mineria galaicas, es la sintesis magníficamente ilustrada de A. Perea y F. J. Sánchez-Palencia dedicada a la arqueología del oro astur (1995).

De índole bien distinta, aunque también obra de síntesis, es la que han entregado Ana Romero Masiá y Felipe Arias Vilas (1995). Estos dos experimentados especialistas se han atrevido con un diccionario de términos de arqueología y prehistoria que, frente a los glosarios al uso, como el de G.Fatás y G. M. Borrás (Diccionario de términos de arte

${ }^{3}$ Un inconveniente que presenta la obra es el de no dar por su número del corpus ni tampoco por la página en que previamente han sido catalogados los distintos ejemplares que se comentan ya en el capitulo $4 .^{\circ}$ de análisis e interpretación de temas: ello impide una localización directa de la pieza en el corpus y obliga a mirar y remimar una y otra vez el índice de yacimientos, pero sobre todo puede en algín momento crear confusión al lector: en la păg. 671 se presupone gratuitamente que este recordará en todo momento que Sta. Comba y Basto son dos topónimos alusivos al mismo yacimiento (el nombre del lugar y el del ayuntamiento) y no dos yacimientos distintos (parece como si se adjudicasen dos piezas a Basto y una a Sta. Comba); en pág. 674.77 se habla del torso de Sta. Adega, pero esta flor de santidad no aparece en el inventario bajo el femenino gailego, sino castellano: Sta. Águeda (n. ${ }^{\circ}$ 72); en las págs. 669 s se habla de Vila Verde (ayuntamiento portugués), pero uno ha de perder tiempo hasta descubrir que la pieza en cuestión aparece indizada por su nombre de lugar, S. Juliâo (n. ${ }^{\circ} 66$ ), al igual que la de Meixedo, en realidad, localizable por $\mathrm{S}$. Paio de Meixedo (n. ${ }^{\circ} 70$ ), etc. Parecen pequeños detalles, pero en una obra de consulta cruzada como un catálogo pueden dificultar el trabajo del lector, al que no debe pedirsele que domine todo el corpus antes de pasar a los capítulos de síntesis historico-artística. Por lo demás, el mapa de la estanuaria sigue haciéndose: ver Fernández de la Cigon̉a 1995. 
y elementos de arqueología y numismática, Zaragoza 1980, reed. Alianza), o el de E.Ocampo (Diccionario de términos artísticos y arqueológicos, Barcelona 1992), tiene la ventaja -ciertamente sólo desde nuestro punto de vista- de incorporar al lenguaje científico la terminología cultural propia de la protohistoria y la historia antigua galaicas, asi como la de suministrar multitud de ejemplos tomados de los yacimientos portugueses, gallegos y asturianos. Hay una serie de voces que el lector interesado en los estudios castreños debería consultar ${ }^{4}$.

Mención aparte merece el libro de Juan L. Naveiro López, El comercio antiguo en el N.W. peninsular. Lectura bistórica del registro arqueológico (La Coruna, 1991), que viene a colmar una laguna reiteradamente señalada desde Maluquer (1975) hasta Eiroa (1988). Se trata de una obra, en principio de historia económica (comercial), aunque por supuesto tambiên de difusión cultural y romanización, que se asienta sobre el estudio de los materiales cerámicos y anforarios exhumados o rescatados del mar, desde el Duero hasta el Navia y entre los siglos v a.C. y II d.C., aproximadamente. Muy importante es la distinción entre áreas dinámicas y abiertas a la penetración comercial romana (la bracarense, las rías bajas), frente a otras marginales, más alejadas o menos favorecidos en sus relaciones con el exterior. Pero mâs importante todavía es la periodización establecida por el autor en lo tocante al desarrollo de las actividades comerciales, en cinco fases, diferenciadas cada una de ellas por sus correspondientes objetos, agentes, modos y medios de intercambio: $1 .^{2}$ ) fase prerromana de contactos mediterráneos, med. s. IVfin. s. II a.C.: control púnico del tráfico atlántico a través de Gadir, a base de intercambios puntuales, pero con cierta regularidad, en las zonas costeras más accesibles y tramos inferiores de los ríos más importantes (vajillas finas y otros productos de lujo constituyen la mayoría de las importanciones); $2 .^{2}$ ) fase de contactos romanos, f. s. Il-1. ${ }^{2}$ m. s. I a.C.: expediciones militares o meramente exploratorias, conducentes al progresivo control de la costa lusitana y bracarense, con introducción de vino y mayor penetración interior por vía fluvial; $3{ }^{a}$ ) fase de conquista y ocupación, med. s. I a.C.-med. S. I d.C.: integración pacífica de las âreas más dinámicas, que son los puntos de apoyo para el ejército de ocupación y sede de los grandes poblados indigenas, al compás de la organización administrativa, todo lo cual coincide con la aparición de moneda y el máximo desarrollo del comercio marítimo a larga distancia, sobresaliendo el vino como primer producto de importación; $4{ }^{2}{ }^{2}$ fase de asimilación y transformaciones, med. s. I-princ./med. s. II d.C.: terminación de la red viaria y puertos, aumento de los núcleos urbanos y notoria modificación del hábitat rural, en paralelo al decaimiento de los tráficos mediterráneos en favor de las rutas atlánticas, al tiempo que mejoran las conexiones terrestres con la meseta e incrementa la producción artesana (momento probablemente más álgido del comercio interior); $5 .{ }^{2}$ ) fase de consolidación y desarrollo interno, med. s. III-s. v d.C.: con-

\footnotetext{
"S6jo a título de muestra cikemos algunos términos de indudable importancia para la arqueología ga-

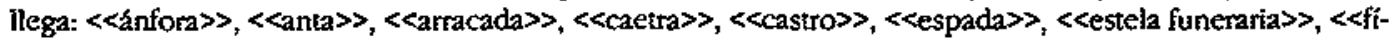

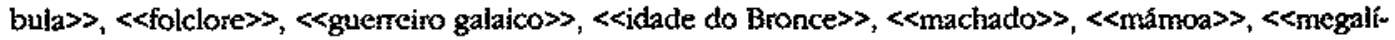

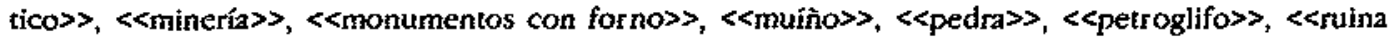

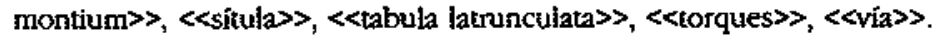


siderable atenuación de la posición marginal del NO en la península con el desplazamiento de los centros económicos, el equilibrio entre mundo rural y las sedes urbanas, con el máximo desarrollo de las villae, cuyos propietarios monopolizan un comercio reducido de productos de lujo a larga distancia.

Quizá lo más sorprendente en este resurgimiento de los estudios castreños sea la ausencia de una figura investigadora con el saber y la capacidad de sintesis de un Florentino López Cuevillas (1886-1958), el nombre más emblemático de toda la arqueología gallega y, como es bien sabido, representante ilustre de la Xeneración NOS. Prueba de lo dicho puede suministrarla el hecho de que la obra ya clásica del orensano, La civilización céltica de Galicia (1953), ha merecido una reedición no hace mucho tiempo (1988), con un estudio preliminar de historiografía a cargo de Gómez-Tabanera, así como un caluroso prólogo de Beltrán Martinez. La síntesis de Cuevillas; superada en muchos aspectos por los nuevos hallazgos, no ha llegado sin embargo a ser reemplazada por ninguna otra monografía del mismo género, lo que no deja de ser llamativo si tenemos en cuenta la mejor preparación técrica de los actuales especialistas y el cúmulo de nuevos datos reunidos en este último cuarto de siglo. Llamativo, pero quizá deba añadirse, no tan sorprendente: a más información, más preguntas y menos simplificadora nuestra reconstrucción de la protohistoria e historia antigua galaicas. En este sentido le es aplicable también a la investigación del mundo castreño lo que David L. Clark señalaba de la arqueología en general a partir de los años sesenta: que también ella ha experimentado la pérdida de la inocencia. Sea como fuere, no debiera olvidarse que el autor de la síntesis esperada sobre el mundo galaico no sólo habrá de tener muy en cuenta los datos concernientes a la prehistoria del Bronce, sino tambiến todos los aspectos relativos a la romanización en Galicia, sin la cual resulta incomprensible el proceso perfectivo de la cultura castreña en su conjuntos.

Decimos pérdida de la inocencia, y decimos bien. Primero se empezó por cuestionar la cronología canónica de un milenio (v a.C.-rv d.C.) propuesta por Cuevillas para la cultura de los castros (Romero, Arias 1995, 59), que ahora sólo se lleva hasta el periodo flavio (CALO, 1994, 782: "hoy todos los autores llevan el remate de la cultura castreña hasta mediados o fin del s. I d.C.") y cuyos siglos iniciales de transición a partir el Bronce final quedan todavía en una cierta penumbra (como ha señalado PARZINGER, 1991), si bien las últímas dataciones absolutas mediante C-14 permiten precisar algo más las co-

\footnotetext{
${ }^{3}$ Esto supone incluir en nuestros análisis, evidentemente, no sólo castros desarrollados en ambiente ya romano, como el de Viladonga y otros más o menos proximos a centros administrativos como Lucus Augusti (Akiss, 1987; Id., DurkN, 1996; RODŔ́GuEZ COLMENERo, coord., 1996, passim), sino también aquellos castros organizados bajo directo control romano, como los mineros del Caurel (LUZON, SÁNCHEZ-PAIENCIA y otros, 1980).
} 
sas $s^{6}$. Luego, algunos arqueólogos en particular declararon la guerra al celtismo', tema y bandera de la historiografia galleguista desde el siglo romántico (JUEGA, 1996), aunque sin arrastrar con ellos a los filólogos (TOvar, 1983; MuLÁN, 1983; UNTERMANN, 1993), ni parece que tampoco a todos los historiadores (GarCí, F. A., 1990; Brañas, 1995); y desde luego la celtización del finisterre galaico queda bastante mitigada en la citada ponencia de Almagro-Gorbea $(1995,123)$, panorámica que en todo caso el lector deberá completar con los recientes contribuciones de los lingüistas (VILLAR, 1995; Id., ENCARNAÇAO, 1996). En otro orden de cosas, se iba a poner en cuarentena la teoría funeraria sobre la esculura de guerreros (ALMEIDA, 1981; ALARÇÂO, 1986, etc.). Y así hasta la actualidad, en que el impacto de la arqueología espacial se deja sentir en una muy afortunada ampliación del cuestionario investigador a la territorialidad, el hábitat y la explotación económica del medio (VÁzquez Varela, 1983a; Carballo, 1986, 1990, 1993, 1996; Carballo, NaVEiro, ReY, 1988; XuSto, 1988/89, 1993; AGRaFoXo, 1989; MartiNS, 1990; CRIADO y otros, 1991; PARCERO, 1995; asimismo BouHER, 1979, con el único mapa de distribución de castros disponible, ya que por desgracia aún no contamos con una mapografia completa del reparto de castros en el noroeste peninsular: número, densidad y ubicación más exactos). En esta arqueología del paisaje, qué duda cabe, interesa no poco la dimensión simbolo-crática de ciertos emplazamientos (FERNÁNDEZ-POSSE, SANCHEZ-PAIENCIA y otros, 1994; CARBALLO, 1996), todo ello antes de plantearnos el fenómeno de las reocupaciones de castros o la sustitución de éstos por los nuevos patrones de asentamiento romano, tipo villa y vicus (ARIAS, 1993; CARBALlo, 1996; CARROCERA, 1996; RODRiGUEZ, COLMENERO, 1996). Es cada vez mayor la conciencia que se tiene de la estructuración regional interna del mundo castreño, esto es, esas individuaciones zonales observadas desde la cultura material (REY, 1995), y en las que los mandatos de la geografía y de la larga duración -que diría Braudel - se matizan con las postdatas que ha ido escribiendo la historia: invasiones, contactos e influencias exteriores, guerras inter-

6 "Desde el punto de vista de la cronología absoluta, la cultura castrefa parece iniciarse entre los siglos vi-v a.C., con su apogeo entre los siglos iv a.C. y I d.C., para ir apagándose a partir del siglo it d.C., aunque sigan perviviendo algunos núclcos aislados, ya muy romanizados, hasta la época tardoantigua", Eiroa 1988, 118. Génesis y sobre todo extinción de lo castreño, precisamente por su caracter difuso, siguen siendo cuestiones abjertas. En cuanto al comienzo, sin embargo, se precisa más ahora, y así resume Rey (1995, 166): "constatamos un ritmo de integración diferenciado entre el territorio bracarense, donde el proceso de castrización comienza en un contexto cronológico cultural del B.F. (X-1X a.C.) (MArtins, 1990, y Sllvs, 1986) y cl resto del territorio del norosste peninsular, donde este parece retrasarse a los comienzos del Hicrro (VII-v) a.C.) DE LA PENa, 1996, 78s, por su parte, propone: fase de formación ( $x-v$ a.C.), fase de desarrollo ( $v$ med.II a.C.), fase castrexo-romana (II a.C.-med. I d.C.), y fase galaico-romana (fin. J-II). Nuevos avances en las dataciones absolutas: Mejide, 1990; CARBallo, FABREGAS, 1991; FERnANDez, RAMIi, 1992; HidAlGo (coord), 1996, 242-244. Recomendamos la síntesis periodológica de la cultura castretia propuesta por REy, 1996, integrando los tiempos relativos (tipológicos) de la cerámica, con las fases radiocarbónicas disponibles (CarbalLo, FábreGAs, 1991), con los ciclos cronologicos de importación de los castros (Navelro, 1991), y con orras series tipologicas conocidas, como la orfebrería y las fibulas.

'Véase el tono polémico característico en DE iA PEÑA, 1996, 67s. Cl. también ElROA, 1996, 21-22. 
nas, receptividad e inventiva de algunas comunidades e individuos capaces de superar las inercias estructurales, etc.

Cuestiones todas ellas de gran relieve que, en suma de cuentas, nos remiten a $1 .^{\circ}$ ) la cronología y a $2^{\circ}$ ) la evolución morfológica o seriación tipológica interna del mundo galaico, las dos grandes asignaturas pendientes de la arqueología castreña, ambas inseparablemente unidas a la correcta interpretación de cualquier secuencia estratigrăfica ${ }^{8}$ Pues, por mucho que, verbigracia, en el ayuntamiento de Santiago se hayan prospectado 27 yacimientos (AA.VV. 1987b), o que en Ferrolterra se hayan catalogado unos 60 (RoMERO, POSE, 1986; AA.VV. 1987a), o que se haya hecho otro tanto con 39 poblados en el término municipal de Lugo (FERRER, GONZÁlEZ, 1996), enormes serán las servidumbres al valernos de tales números para la historia agraria, demográfica y habitacional, o al estudiar la ocupación y organización del territorio, si desconocemos la cronología de cada castro y los lapsos temporales exactos de coexistencia entre ellos (y de esto son lógicamente conscientes los investigadores hoy día: por ej., FERRER, GONZÁlEZ, 1996, 391,410). Bien al contrario, por ello mismo, se nos presentarán las zonas con asentamientos excavados, como los 5 muy próximos del valle medio del río Deza (Carballo, 1986, 1996, 1997). Incluso se abren serios interrogantes sobre la verdadera facies de lo castreño, sobre la propia homogeneidad cultural de los galaicos (esa unidad étnica al fin y al cabo definida por Roma), habida cuenta de que gran parte de los objetos y construcciones considerados típicos o más desarrollados se inscriben ya en la órbita de la romanización (DE LA PEÑA, 1996, 88-89). Por otra parte, no todos los trabajos de prospección y catalogación han sido realizados con la misma meticulosidad y competencia profesional -las planimetrías son en muchos casos sólo aproximadas, quizá ya incorregibles a causa del deterioro constante del patrimonio-, ni los hallazgos de materiales terminan siempre en instituciones públicas que los preserven para su estudio y exposición, razones todas ellas por las que no siempre resultan comparables, ni combinables, ni extrapolables los resultados obtenidos. He ahi por tanto los grandes retos de la arqueología castreña: rescatar, inventariar y conservar activamente el patrimonio, contrastar e integrar conocimientos, homologar las técnicas de trabajo y, no menos aún, planificar en forma adecuada las labores de prospección y excavación.

A todo lo dicho acaso debería añadirse la conveniencia de continuar e impulsar los trabajos ya iniciados de arqueología subacuática (SENÉN, 1983; RODŔ́GUEZ, 1985/86; DE LA PEÑA, 1984; HIDALGO, SOTELo, 1985), por razones que no es menester explicar, habida cuenta de la gran cantidad de poblados de tipo marítimo (en rías y desembocaduras de ríos, cerros costeros, penínsulas, islas, etc.) y de la tradición naval y pesquera en las tías desde la prehistoria (ALMAGRO-GORBEA, 1995b; ALONSO ROMERO, 1995a/b; a los que cabe añadir: ANTONA, BLÁNQUEZ y otros, 1988, para una buena visión panorámica de la arqueología subacuática en España).

${ }^{6}$ Nos gustaría saber, por cierto, qué posibilidades y ventajas tendría en la excavación y publicación de yacimientos castreños de cierta potencia y complejidad estratigráficas (caso de Cameixa o Torroso o Penalba) la aplicación del Matrix-Harris, con toda la reconceptualización del análisis estratigráfico que este método conlleva: vid. HaRRIs, 1991 
A la espera de que llegue el momento de abordar con suficiente solvencia esos nuevos problemas, sepa el lector que cuenta con una serie de manuales e historias generales que pueden servir como introducción a los estudios castreños (VÁZQUEZ VARELA, 1993; BELLO, DE LA PEÑA, 1995), sin olvidar por supuesto el horizonte de la romanizaciôn (Tranoy, 1981; Amado, Pereiro, 1991; ARIas, 1992). Pero si tuviéramos que escoger algún título de los últimos años, probablemente las síntesis más recomendables serían estas dos: la elaborada por un colectivo de profesores universitarios (AcuNia, GARCiA QUINTELA, NAVEIRO, VAZZUEEZ VARELA, 1991), y la firmada por Calo Lourido (1993), ambas por lo demás perfectamente complementarias. A ellas sumariamos, a modo de estado de la cuestión, las actas del curso de verano de la Universidad de Vigo, celebrado en Tuy, del 17 al 19 de julio de 1995, con la coordinación de Hidalgo Cuñarro: A cultura castrexa a debate (TUY, 1996). Las colaboraciones incluidas en este libro, que ya hemos ido citando en las líneas precedentes, se ocupan de temas tan centrales como la cultura céltica en la península Ibérica (Eiroa), historiografía e investigación de la cultura castreña en Galicia (Acuña), el mito del celtismo en Galicia (Juega), la secuencia cultural del mundo castreño galaico (De la Peña), el espacio en la cultura castreña de Galicia (Carballo), religión y sociedad en el mundo castreño gallego (García F. A.), referencias de tiempo en la cultura material de los castros gallegos (Rey), el fin de la cultura castreña (Carrocera), amén de un resumen sobre las excavaciones en el castro de Troña (Hidalgo).

Tanto de estas obras generales, como de los diccionarios y las monografias, se desprende que en nuestra visión de la cultura castreña han ganado precisión los perfiles de las distintas fases y técnicas de su cerámica (REY, 1990/91, 1991, 1996, 160s); hasta cierto punto también las formas del hábitat, las viviendas y la fortificación, aunque persistan dudas en algunos aspectos (CALO, 1993, 97s; BELLO, DE LA PEÑA, 1995, 164-5; DE LA PEÑA, 1996, 80-81; BRAÑAs, 1995, 332), y el libro ya clásico de Romero (1976) debiera ser actualizado, a poder ser por la propia autora, a la luz de las nuevas excavaciones (véease la contribución posterior de ALMEIDA, 1984); los aspectos concernientes a la tipología de los poblados y las estratigrafías (Arqueoloxía/Memorias, Xunta de Galicia); los de sus artes plásticas (CALO, 1994); los de su tecnología orfebre (PÉREZ OUTEIRIÑo, 1982; CASTRO, 1990; BaLseiro, 1995, 1997) y fibular (FARjÑa, ARIAS, 1983; CoRTegoso, VINAs, 1994/95); y aun con todos los interrogantes, los de sus contactos con el exterior (NAVEIRO, 1991, 1994; PARZINGER, 1991; HIDAlGo, 1995; ChIC, 1995). Parece cobrar fuerza la idea de que los llamados "monumentos con homo", situados por lo general en áreas periféricas de los castros de época galaico-romana (Briteiros, Sanfíns, Coaña, Punta dos Prados, Cidá de Armeá, etc.), cumplían la función de sauna o, si se prefiere, de termas (CALO, 1993, 149s; AlMAGRO-GORBEA, ÁlVAREZ-SANCHIS, 1993; ARIAS, 1997, 209-210). Hay además trabajos de detalle, concienzudos y minuciosos, que demuestran la gran capacidad correctora, o cuando menos enriquecedora, que la arqueología puede tener frente a los cliches y las parcialidades de los autores grecorromanos: ahí están los análisis carpológicos y polínicos que documentan trigo, cebada, mijo, haba, y acaso también avena y centeno, amén de una fuerte deforestación (ARNANZ, CHAMORRo, 1990; AIRA y otros, 1989, 1990; RODRIGUEZ LOPEZ y otros, 1993), parámetros analíticos que se complementan con los edafológicos (MARTíNEZ, MOARES, 1995); al paso que, en un aspecto culturalmente tan 
importante como la dieta, los trabajos de Vázquez Varela (1975a/b, 1983b, 1993/94, y en colaboración con CaNo PAN, 1991; con ReY SALGADO, CAMINO, 1993; y con URGORRI, TrONCOSO. 1993) nos demuestran que no todo encajaba simplemente en la tríada antimediterránea, y por tanto bárbara, que Estrabón $(3.3 .7 ; 4.10$ ) asignaba por igual a los pueblos del norte de lberia, incluidos los galaicos: cerveza en lugar de vino, grasa de animal en vez de aceite y bellotas a falta de pan de trigo (ALONSO DEL REAL, 1979; BERMEJO, 1986, 21s). Antes al contrario, parece probado que también la pesca y el marisqueo tenían una amplia cabida en ese aspecto esencial de la cultura que Lévi Strauss estudió en sus Mitológicas (ver últimamente FERNÁNDEZ, RODRfGUEZ, 1996).

No quisiéramos cerrar este modesto informe sin proponer un modelo de análisis para la época galaico-romana tomado de la moderna antropología colonial. En los últimos años se viene insistiendo en que la conquista de Gallaecia por los romanos no suscitó la misma resistencia que entre los pueblos vecinos (lusitanos, cántabros y astures), al menos en la fase final de la conquista, bajo Augusto (29-19 a.C.). En relación con esto se ha llamado la atención sobre las distintas manifestaciones (urbanísticas, ergológicas, políticas y espirituales) de un proceso al parecer consentido de romanización, cuando menos en lo que respecta a las élites indígenas. Cuidémonos mucho de simplificar las cosas, mas fuera como fuese dicho proceso, debe saberse que el gran tema del bilingüismo y la diglosia, del mestizaje cultural y de la confrontación, está siendo objeto de vivo estudio en otras áreas y épocas del mundo antiguo'. Quizá no siempre se trate de un enfrentado y cortante dualismo, asimilación o resistencia ante el invasor (ALMEIDA, 1986), sino de un comportamiento más complejo y articulado. En concreto, para la penetración greco-macedonia en el oriente helenístico, para la génesis y desarrollo de la $<<$ sociedad colonial > organizada por los herederos de Alejandro, Édouard Will (1985) explicó de manera convincente la utilidad de una tétrada analítica tipificada por G.Balandier a partir de la moderna sociología colonial de la dependencia, en concreto, el espectro teórico de reacciones de los conquistados frente a los conquistadores:

1. La aceptación activa, que implica un alto grado de aculturación y en la que normalmente sólo se compromete una minoría, proviene no sólo de los notables beneficiados con el colaboracionismo (élites municipales), sino también de aquellas personas de condición humilde deseosas de medrar a favor de los nuevos tiempos (esclavos y libertos imperiales). Sería el caso de las estatuas de guerreros galaicos, pero también de buena parte de la epigrafia que incluye onomástica latina ${ }^{10}$, de los enclaves aledaños a los centros de romanidad pura y dura (a ciudades como Lugo y Braga, a campamentos como Ciudadela y Ban-

"Para los estudios relativos al mundo helénico, véase Aionso Troncoso, 1994: Pautas y guiones para una bistoria de Grecia, Tórculo Ed., Santiago (temas 38, 40, 41, y especialmente 42).

${ }^{10}$ Resulta de especial relevancia en este contexto el trabajo de GARCiA MARTiNeZ, 1995, ponque incide de manera directa en los distintos grados de integración romana que apuntan los epígrafes funerarios, un estudio realizado a partir de un corpus de casi 500 lápidas pertenecientes a los conventos lucense y astur. 
de, pero también a las vías romanas y a los emporios costeros más visitados). Y finalmente, claro está, la siruación en la que se hallarian los habitantes de las villae tardias. Es posible que las primeras expresiones de este talante abierto provengan de la importación de vino y aceite por parte de los jefes galaicos, dispuestos a entrar en contacto beneficioso con el extranjero, según atestigua el comercio anforario (NAVEIRo, 1991) y está asimismo bien estudiado por A.Tchernia para la Galia ("Italian wine in Gaul at the end of the Republic", en GARNSEY, HOPKINS, WHITTAKER, 1983, 87s), y más recientemente por C. Gómez y P.Guerin para la cultura ibérica ("Témoignage d'une production de vin dans l'Espagne préromaine", en AMOURETT, BRUN, 1993, 379-395). Indudablemente la formación de unidades auxiliares de galaicos en el ejército romano es otra prueba de la apertura a la que aquí nos referimos (SANTOS, 1988), lo mismo que los pactantes indígenas de las tesserae y tabulae de hospitalidad, tres, conocidas en Galicia (más dos en Astorga y dos en Vila Nova de Gaia) (ARIAS, 1992, 87s).

2. La aceptación pasiva, por el contrario, es cosa de mayorías - los "colonos típicos"- $y$, por ejemplo, en el oriente lágida o seléucida constituye la respuesta normal de las poblaciones campesinas, que a veces ni siquiera perciben con claridad la imposición de un nuevo orden políico. La aparición en numerosos castros de elementos ergológicos romanos y nuevos parámetros constructivos, más que epigráficos y religiosos, estaria indicando esta corriente general y progresiva, que terminará con la asimilación del latín por todo el pueblo galaico - fruto y testimonio irrefutable de la romanización-.

3. La oposición pasiva puede ser la otra cara de la impotencia popular ante los colonizadores, si bien en este caso de carâcter negativo, casi siempre como una disposición más anárquica e individual que organizada: la huida de los centros de trabajo y de los lugares de residencia, el incumplimiento de pagos y servicios obligatorios, la cerrazón a la lengua extranjera, el apego exclusivo a los cultos indigenas, etc. Como actitud mental que es, no resulta infrecuente que subyazcan en la misma sentimientos religiosos dificiles de desarraigar. Quizá aquellos castros mas arcaizantes y con menores signos de romanización, quizá también los más apartados o los aislados en las áreas montañosas, puedan estar evidenciando a partir del s. I d.C. tendencias refractarias a la novedad, por no hablar de la persistencia de determinados dioses y ritos de sustrato prerromano, o quizá también de las reocupaciones tardias de castros (estado de la cuestión al respecto: Carrocera 1996). ¿Qué estarian significando el priscilianismo y el anacoretismo tardíos a la luz de todo ello? ¿Qué información podría revelar en esta línea de análisis las denuncias de un San Martín de Dumio? (ver López Pereira 1992).

4. La oposición activa viene dada en principio por la resistencia abierta a los extranjeros, en forma de guerra regular o de guerrillas, de revueltas sociales organizadas y violentas, etc. En la historiografia romántica, y también en la ga- 
lleguista de este siglo, la libertad de los galaicos tenía su canto de cisne en la inmolación colectiva del monte Medulio, que hoy en cambio tiende a situarse fuera de la Galicia actual. Pero no se debe soslayar el hecho de que este comportamiento positivo y militante se puede expresar de manera no necesariamente violenta, sino también en el plano socio-cultural, frente a cualquier brote de aculturación.

\section{BIBLIOGRAFIA}

acuña Castroviejo, F. (1977): "Panorama de la cultura castrexa en el N.O. de la Península Ibérica", Bracara Augusta 31, 235-253.

- (1991): A) "Algunas cuestiones previas sobre la cultura castrexa", B) "Los asentamientos", C) "Aspectos artisticos", en AA.VV., Galicia-Historia, I, Santiago, 287-93, 295305, 307-313.

- (1996): "Historiografía e investigación da cultura castrexa en Galicia", en Hidalgo (Coord.), 1996, 27-39.

AGRAFOXO PEREZ, X, (1989): O poboamento castrexo na rexión occidental da provincia da Coruña, Santiago.

AIRA RODRfGUEZ, M. ${ }^{2}$ J; SAA OTERO, P., y TABOADA, T. (1989): Estudios paleobotánicos y edafológicos en yacimientos arqueológicos de Galicia, Arqueoloxía / Investigación 4, Santiago.

Aira Rodríguez, M." J.; Ramil Rego, P., y Állvarez NứNEz, A. (1990): "Estudio paleocatpológico realizado en el castro de Penalba (Campo Lameiro, Pontevedra, España)", Botanica Complutensis 16, 81-89.

ALARGAO, J. (1986): "Arte do bronze final e da idade do ferro", en Historia da arte em Portugal. 1): Do paleolítico à arte visigótica, Lisboa, 57-65.

- (Coord.) (1990): Portugal. Das origens à romanizaçao, vol. I de la Nova História de Portugal, Lisboa.

- (1992): "A evoluçâo da cultura castreja", Conímbriga 31, 39-71.

ALFARO GINER, C. (1984): Tejido y cestería en la península lbérica. Historia de su técnica $e$ industrias desde la prebistoria hasta la romanización, Madrid.

ALMAGRO-GORBEA, M., y ÁlvAREZ-SANCHIS, Y. (1993): "La "Fragua" de Ulaca): saunas castreñas y baños iniciáticos en el mundo céltico", Cuad. Arqueol. Univ. Navarra 1, 177-253.

ALMAGRO-GORBEA, M. (1995a): "Secuencia cultural y etnogénesis del centro y noroeste de la peninsula Ibérica", Actas 22 CNA. Vigo 1993, I, Vigo, 121-136.

- (1995b): "La navegación prehistórica y el mundo atlántico", en AlONSO Troncoso (Coord.), 1995, 13-35. 
ALMEIDA, C. A., y FerReira de (1981): "Nova estátua de guerreiro galaico-minhoto (Refojos de Basto)", Arqueologia 3, Grupo de Estudios Arqueológicos do Porto, 111-16.

- (1984): "A casa castreja", $M H A$ 6, Oviedo, 35-42.

- - (1986): "A arte castreja. A sua liçao para os fenómenos de assimilaçao e resisténcia á romanidade", Arqueologia 13, 161-172.

ALONSO DEL REAL, C. (1975): "Dificultad y necesidad de un saber prehistórico", Gallaecia 1, 7-23.

- (1979): "Estrabón revisitado", Gallaecia 3/4, 53-69.

Alonso ROMERO, F. (1995a): "La embarcación del petroglifo Laxe Auga dos Cebros. (Pedornes, Santa Maria de Oia, Pontevedra)", en Actas 22 CNA. Vigo 1993, II, Vigo, 137-145.

- (1995b): "Las embarcaciones y navegaciones en el mundo celta, de la edad antigua a la edad media", en ALONSO TRONCOSO (Coord.), 1995, 111-145.

ALONSO TRONCOSO, V. (Coord.) (1995): Guerra, exploraciones y navegación): del mundo antiguo a la edad moderna, La Coruña.

- "Primeras etapas en la conquista romana de Gallaecia", Militaria 8, 53-66.

- (Ed.) (1997); Ferrolterra galatco-romana, Ferrol (en prensa).

ÁLVAReZ NúNez, A. (1986): Castro de Penalba. Campaña 1983, Arqueoloxia/Memorias 4, Santiago.

Álvarez-SANCHIS, J. R. (1995): "Esculturas de verracos y etnicidad en el contexto de la romanización", Actas 22 CNA. Vigo 1993, II, Vigo, 343-347.

Amado RodrfGuez, M." T., y PERelro Pardo, A. C. (1991): Bibliografía da Galicia romana, la Coruña.

AMOURETT, M.-C., y BRUN, J.-P. (1993): Laproduction du vin et de l'buile en Méditerranée, Paris.

ANTONA, V., y BLÁNQUEZ, J. et alii (1988): La arqueología subacuática en España, Ministerio de Cultura, Madrid.

ARIAS VILAS, F. (1985): Castro de Viladonga. Campaña 1983, Arqueoloxía / Memorias 2, Santiago.

- (1987): "Castros lucenses de época romana", $M H A$ 8, Oviedo, 7-16.

ARIAS VILAS, F. et alii (1990): Museo del castro de Viladonga, Madrid.

ARIAS VHAS, F. (1992): A romanización de Galicia, Vigo.

- (1993): "Apuntes sobre a ocupación do territorio na Galicia baixorromana): castros e vilas", en AA.VV., 1993, 201-208.

ARIAS VIlas, F., y DURÁN FUENTES, M. C. (1996): Museo do castro de Viladonga (en gall., esp., ingl., fr. y alem.), Xunta de Galicia, Santiago.

ARIAS VILAS, F. (1997); "As influencias romanas no urbanismo castrexo" (bilingüe), en A.A.V.V., 1997, 205-210. 
ARNANZ, A. M., y CHAMORRO, J. (1990): "Estudio de frutos y semillas procedentes de cuatro castros gallegos. Problemas en la interpretación de los resultados", en Encontros sobre paleoeconomia e paleoambiente, Vila Nova de Famaliçao.

AA.VV. (1979): Prebistoria e arqueoloxía de Galicia. Estado da cuestión, Sección de Arqueoloxía e Prehistoria do I.E.G.P.S. do C.S.I.C., Lugo.

- (1987a, Catalogación castrexa da bisbarra de Ferrol, Cuademos do Ateneo Ferrolán 5, Ferrol.

- (1987b): Catalogación de yacimientos prerromanos del ayuntamiento de Santiago, Arqueoloxía / Investigación 3, Santiago.

- (1989): El oro en la España prerromana, Rev. Arqueología, Madrid.

- (1991a): Ciudad y torre. Roma y la llustración en La Coruña, La Conuna.

- (1991b): Galicia no tempo-1991, Santiago.

- (1993): Galicia): da romanidade á xermanizaciōn. Problemas histónicos e culturais. Actas do encontro científico en bomenaxe a Fermin Bouza Brey (1901-1973), Santiago.

- (1995): Actas del XXII Congreso Nacional de Arqueología. Vigo 1993, I-II, Vigo.

- (1997): Galicia castrexa e romana / Galicia castreña y romana, Programa Expositivo $\ll$ Galicia, terra única $\gg$, Lugo.

Balil IllanA, A. (1977): "Excavaciones en Torres do Oeste de Catoira (Pontevedra)", Noticiario Arqueológico Hispánico, Arqueologia, 5, 379-385.

BAISEIRO GARCIA, A. (1995): El oro prerromano en la provincia de Lugo, Lugo.

- (1997): "Aproximación a la orfebrería castreña): el tesoro Bedoya", en ALONSO TrONCoso (Ed.), 1997, en prensa.

BeLLO, J. M., y DE LA PEÑA, A. (1995): Galicia na prebistoria, Oleiros (Coruña).

BERMEJO BARRERA, J.C. (1978); La sociedad en la Galicia castreña, Santiago.

- (1986): Mitologia y mitos de la Hispania prerromana 2, Madrid.

Blanco Frejeiro, A., y Filgueira Valverde, J. (1954): "Nuevas joyas prehistóricas gallegas. El tesoro Bedoya", CEG 9, 161-180.

BLANCO FREjEIRO, A. (1957): "Origen y relaciones de la orfebreria castreña", CEG 12, 5 28, 137-157, 267-301.

BOUHIER, A. (1979): La Galice. Essai géographique d'analyse et d'interprétation dun vieux complexe agraire, I-II, La Roche-sur-Yon.

BRAÑAS, R. (1995): Indíxenas e romanos na Galicia céltica, Santiago.

CALO LOURIDO, F, y SierRa Rodríguez, J.C. (1983): "As orixes do castrexo no bronce final", en PEREIRA (Ed.), 1983, $19-85$.

Calo lourido, F., y Soeiro, T. (1980): Castro de Baroña. Campañas 1980-84, Arqueoloxía / Memorias 6, Santiago. 
CALO LOURIDO, F. (1993); A cultura castrexa, Vigo.

- (1994): A plástica da cultura castrexa galego-portuguesa, I-Il, La Coruña.

- (1997): "Artes plásticas, cultos e ideoloxía na Galicia castrexa" (bilingüe), en A.A.V.V., 1997, 92-99.

CANO PAN, J., y VÁZquEZ VARELA, J. M. (1991): "El aprovechamiento del mar en los castros costeros de Lugo (Galicia)", Paleoecologia e Arqueologia, II, Vila Nova de Famaliçao, 71-75.

CARBALlO ARCEO, L. X., y REY CASTIÑEIRA, J. (1985): Catalogación arqueológica del municipio de Santa Comba, Santiago.

CARBALlo ARCEO, L. X. (1986): Povoamento castrexo e romano da terra de Trasdeza, Arqueoloxía / Investigación 2, Santiago.

- (1987): Castro da Forca. Campaña 1984, Arqueoloxía / Memorias 8, Santiago.

CARBallo ARCEO, L. X.; NAVEIRO, J. L., y REY, J. (1988): "Problemas de compartimentación espacial do castrexo galaico", en Coloquio de Arqueologia do Noroeste Peninsular, (TAE 28), Porto, 167-84.

CARBallo ARCEO, L, X. (1990): "Los castros de la cuenca media del río ulla y sus relaciones con el medio físico", Trabajos de prebistoria 47, 161-199.

CARBALlo ARCEO, L. X., y FÁbReGas VALCARCE, R. (1991): "Dataciones de carbono 14 para castros del noroeste peninsular", AEA 64, 244-264.

CARBallo ARCEO, L. X. (1993): "Espacio e povoamento castrexo de Galiza", en Concepcións espaciais e estratexias territoriais na bistoria de Galicia, Asociación Galega de Historiadores, Santiago, 55-82.

- (1994): Catálogo dos materiais arqueolóxicos do museu do Castro de Santa Trega): Idade do Ferro, 2." ed., La Guardia.

- (1996): "Os castros galegos): espacio e arquitectura", Gallaecia 14/15, 309-357.

-- (1997): "Excavación dos castros do Marco e de Cartimil no val do Deza", Gallaecia 16, 231-264.

CARDOZO, M. (1985): Catálogo do Museu de Martins Sarmento. Seç̧ao de epigrafia latina $e$ de escultura antiga, 3." ed., Guimarâes.

- (1996): Citania de Briteiros e castro de Sabroso. Noticia descritiva para servir de guia ao visitante, Guimarâes.

CARrocera FernándeZ, E., y Jorda Pardo, J. F. (1988/89): "Medio geológico y hábitat en los poblados fortificados del occidente asturiano", Castrelos 1-2, 121-138.

CARROCERA FERNÁNDEZ, E. (1990): "El horizonte cultural castreño del occidente asturiano y sus relaciones exteriores", Gallaecia 12, 135-138.

- (1994): "Estudio crítico de la cultura castreña asturiana", Actas do $1 .{ }^{\circ}$ Congresso de Arqueologia Peninsular, Porto, 213-227.

- (1996): "El fin de la cultura de los castros", en HIDAlgo (Coord.), 1996, 209-222. 
- (1989): La civilización céltica de Galicia (reed. de 1953), Madrid.

López CueVllLAS, F., y LOREnzo Fernández, X. (1986): Castro de Cameixa. Campañas 1944-46, Arqueoloxía / Memorias, f.c., Santiago.

LÓPEZ MONTEAGUDO, G. (1989): Esculturas zoomorfas celtas de la peninsula ibérica, Madrid.

LÓPEZ PEREIRA, X. E. (1989): O primeiro espertar cultural de Galicia. Cultura e literatura nos s. IV e V, Santiago.

LuZÓN NoGuE, J. M., y SÁNCHEZ-PALENCIA, F. J. et alii (1980): El Caurel, E.A.E. 110, Madrid.

MALUQUER, J. (1975): "Formación y desarrollo de la cultura castreña", en AA.VV., IJornadas de metodologia aplicada a las ciencias bistóricas. Prebistoria e bistoria antigua, Santiago, 269-284.

MARTINEZ CORTIZAS, A., y MOARES DOMÍNGUEZ, C. (1995): Edafología y arqueología. Estudio de yacimientos arqueológicos al aire libre en Galicia, Santiago.

MARTinez TAMUXE, J. (1995): Citania y museo arqueológico de Sta. Tecla, 3." ed., La Guardia.

MARTINS, M." M. (1988): "A arqueologia dos castros do norte de Portugal): balanço e perspectivas de investigaçao", Coloquio de Arqueologia do Noroeste Peninsular, (TAE 28), Porto, 11-36.

- (1990): O povoamento proto-bistórico e a romanizaçâo da bacia do curso médio do Cávado, Braga.

MAYA GONZALEZ, J. L. (1988): La cultura material de los castros asturianos, Barcelona.

- (1989): Los castros en Asturias, Gijón.

Meijide CAMESElle, G. (1990): "Tres dataciones de C 14 del castro de A Graña (Toques, A Coruña) y su contexto arqueológicon, Gallaecia 12, 111 134.

MENGHIN, W. (1980): Kelten, Römer und Germanen. Archäologie und Geschichte, Múnich.

MLLÁN, I. (1983): "El anticeltismo de Francisco Martins Sarmento", I Coloquio GalaicoMinhoto, I, Braga, 45-109.

MONTEAGUdo, L. (1946/47): "Galicia en Ptolomeo", CEG 2, 609-653.

NAVEIRO LÓPEZ, J. L. (1991): El comercio antiguo en el N.W. peninsular. Lectura bistórica del registro arqueológico, La Coruna.

- (1994): El golfo ärtabro. Arqueología e bistoria del puerto de los galaicos lucenses, La Coruña.

ORERo GrANDAL, L. (1988): Castro Coto do Mosteiro. Campañas 1984-1985, Arqueoloxia/ Memorias 10, Santiago.

PARCERo OUBIÑa, C.): "Aproximación al espacio social en el mundo castreño", Actas 22 CNA. Vigo 1993, II, 185-188.

PARZINGER, H. (1991): "O mundo continental e Galicia na idade de ferro. Reflexións acerca da diadema de Ribadeo", en AA.VV., Galicia no tempo-1991, Santiago, 25-42. 
PENA, A.; MERLAN, E., y FLGUeIrA, A. (1995): Narón. Unba bistoria ilustrada na terra de Trasancos, Narón (Coruña).

PEÑA SANTOS, A. DE LA (1986): Yacimiento galaico-romano de Santa Trega. Campaña 1983, Arqueoloxía / Memorias 5, Santiago.

- (1984): "Primeras prospecciones arqueológicas subacuáticas en el litoral de la provincia de Pontevedra", Pontevedra Arqueológica 1, 205-263.

- (1992, Castro de Torroso. Sintesis de las memorias de las campañas de excavaciones 1984-1990, Arqueoloxía / Memorias 11, Santiago.

- (1996): "La secuencia cultural del mundo castrexo galaico", en HIDALGO (Coord.), 1996, 65-103.

PEREA CAVEDA, A., y SANChez-PALENCIA, F. J. (1995): Arqueologia del oro astur Orfebreria $y$ mineria, Oviedo.

PeREIRA MENAUt, G. (Ed.) (1983): Estudos de cultura castrexa e bistoria antiga de Galicia, Santiago.

PÉREZ OUTEIRIÑo, B. (1982): De ourivesaria castrexa. I. Arracadas, Orense.

- (1985): "Informe sobre las excavaciones arqueológicas de "A Cidade" de San Cibrán de Las (San Amaro-Punxín, Orense), Campaña 1982", N.A.H. 22, 24-259.

- (1989, Orfebreria castreña, en AA.VV., 1989, 90-107.

Pingel, V. (1991): "O tesouro de Caldas de Reis e a ourivería da época do bronce", en A.A.V.V., Galicia no tempo-1991, Santiago, 43-58.

POMBo Moseuera, X. A. (1993): "Os castros nas terras de Vilalba", en A.A.V.V. 1993, $177-190$.

PONTE, M., y SALETE, D. A. (1989): "As fibulas do bronze final atlántico / $1 .^{2}$ idade do ferro do noroeste peninsular. Abordagen e enquadramento cultural", TAE 29, 73-79.

RENFREW, C. (1972): The emergence of civilization. The Cyclades and the Aegean in the third millenitum B.C., Londres.

REY CASTINEEIRAS, J. (1984): "Estudio y catalogación de castros de la provincia de La Coruña", Gallaecia $7 / 8,59$ s.

- (1986, Informe sobre las excavaciones arqueológicas del castro de "O Barral" (Recarea, La Coruña), Santiago.

- (1990/91): "Cerámica indígena de los castros costeros de la Galicia occidental): rías bajas. Valoración dentro del contexto general de la cultura castreña", Castrelos 3/ 4, 141-163.

- (1991): Yacimientos castreños de la Vertiente Atläntica): análisis de la cerämica indigena, tesis microf. n. ${ }^{\circ} 185$, Servicio Publ. de la Univ., Santiago.

- (1995, "Cuestiones de tipo territorial en la cultura castreña", Actas 22 CNA. Vigo 1993, II, Vigo, 165-171. 
- (1989): La civilización cêltica de Galicia (reed. de 1953), Madrid.

LOPEZ CueVIllas, F., y LORENZo Fernández, X. (1986): Castro de Cameixa. Campañas 1944-46, Arqueoloxia / Memorias, f.c., Santiago.

LOPEZ MONIEAGUDO, G. (1989): Esculturas zoomorfas celtas de la peninsula ibêrica, Madrid.

LOPEZ PEREIRA, X. E. (1989): Oprimeiro espertar cultural de Galicia. Cultura e literatura nos s. IV e $V$, Santiago.

LuZÓN NOGUÉ, J. M., y SÁNCHEZ-PALENCIA, F. J. et alii (1980): El Caurel, E.A.E. 110, Madrid.

MALUQUER, J. (1975): "Formación y desarrollo de la cultura castreña", en AA.VV., IJornadas de metodologia aplicada a las ciencias bistóricas. Prebistoria e bistoria antigua, Santiago, 269-284.

MARTINEZ CORTIZAS, A., y MOARES DOMfNGUEZ, C. (1995): Edafología y arqueología. Estudio de yacimientos arqueológicos al aire libre en Galicia, Santiago.

MARTINEZ TAMUXE, J. (1995): Citania y museo arqueológico de Sta. Tecla, 3. ${ }^{2}$ ed., La Guardia.

MARTINS, M. ${ }^{2}$ M. (1988): "A arqueologia dos castros do norte de Portugal): balanço e pers pectivas de investigaçao", Coloquio de Arqueologia do Noroeste Peninsular, (TAE 28), Porto, 11-36.

- (1990): O povoamento proto-bistórico e a romanizaçâo da bacia do curso médio do Câvado, Braga.

MAYA GONZÁLEZ, J. L. (1988): La cultura material de los castros asturianos, Barcelona.

- (1989): Los castros en Asturias, Gijón.

Meijide CAMESElie, G. (1990): "Tres dataciones de C 14 del castro de A Graña (Toques, A Coruña) y su contexto arqueológico", Gallaecia 12, 111-134.

MENGHiN, W. (1980); Kelten, Römer und Germanen. Archäologie und Geschichte, Múnich.

MHIÁN, I. (1983): "El anticeltismo de Francisco Martins Sarmento", I Coloquio GalatcoMinboto, 1, Braga, 45-109.

MONTEAGUdo, L. (1946/47): "Galicia en Ptolomeo", CEG 2, 609-653.

NAVEIRO LÓPEZ, J. L. (1991): El comercio antiguo en el N.W peninsular. Lectura bistórica del registro arqueológico, La Conña.

- (1994): El golfo ártabro. Arqueología e bistoria del puerto de los galaicos lucenses, La Coruña.

ORERo GRANDAL, L. (1988): Castro Coto do Mosteiro. Campañas 1984-1985, Arqueoloxía/ Memorias 10, Santiago.

ParCero Oubiña, C.): "Aproximación al espacio social en el mundo castreño", Actas 22 CNA. Vigo 1993, II, 185-188.

PARZINGER, H. (1991): "O mundo continental e Galicia na idade de ferro. Reflexións acerca da diadema de Ribadeo", en AA.VV., Galicia no tempo-1991, Santiago, 25-42. 
PENA, A.; MERLAN, E., y FilgueIRA, A. (1995): Narón. Unha bistoria ilustrada na terra de Trasancos, Narón (Coruña).

PENA SANTOS, A. DE LA (1986): Yacimiento galaico-romano de Santa Trega. Campaña 1983, Arqueoloxía / Memorias 5, Santiago.

- (1984): "Primeras prospecciones arqueológicas subacuáticas en el litoral de la provincia de Pontevedra", Pontevedra Arqueológica 1, 205-263.

- (1992, Castro de Torroso. Sintesis de las memorias de las campañas de excavaciones 1984-1990, Arqueoloxía / Memorias 11, Santiago.

- (1996): "La secuencia cultural del mundo castrexo galaico", en Hidalgo (Coord.), 1996, 65-103.

Perea CAVEDA, A., y SÁNChez-Palencia, F. J. (1995): Arqueología del oro astur Orfebrería $y$ mineria, Oviedo.

PEREIRA MENAUT, G. (Ed.) (1983): Estudos de cultura castrexa e bistoria antiga de Galicia, Santiago.

PEREZ OUTEIRIÑo, B. (1982): De ourivesaria castrexa. I. Arracadas, Orense.

- (1985): "Informe sobre las excavaciones arqueológicas de "A Cidade" de San Cibrán de Las (San Amaro-Punxín, Orense), Campaña 1982", N.A.H. 22, 24-259.

- (1989, Orfebreria castreña, en AA.VV., 1989, 90-107.

PINGEl, V. (1991): "O tesouro de Caldas de Reis e a ourvería da época do bronce", en A.A.V.V., Galicia no tempo-1991, Santiago, 43-58.

POMio MosquerA, X. A. (1993): "Os castros nas terras de Vilalba", en A.A.V.V. 1993, 177-190.

PONTE, M., y SALETE, D. A. (1989): "As fibulas do bronze final atlántico / $1 .^{2}$ idade do ferro do noroeste peninsular. Abordagen e enquadramento cultural", TAE 29, 73-79.

RENFREW, C. (1972): The emergence of civilization. The Cyclades and the Aegean in the third millenium B.C., Londres.

REY CASTINEEIRAS, J. (1984): "Estudio y catalogación de castros de la provincia de La Coruña", Gallaecia $7 / 8,59$ s.

- (1986, Informe sobre las excavaciones arqueológicas del castro de "O Barral" (Recarea, La Coruña), Santiago.

- (1990/91): "Cerámica indígena de los castros costeros de la Galicia occidental): rías bajas. Valoración dentro del contexto general de la cultura castreña", Castrelos 3/ 4, 141-163.

- (1991): Yacimientos castreños de la Vertiente Atlântica): análisis de la cerámica indigena, tesis microf. n. ${ }^{\circ} 185$, Servicio Publ. de la Univ., Santiago.

- (1995, "Cuestiones de tipo territorial en la cultura castrena", Actas 22 CNA. Vigo 1993, II, Vigo, 165-171. 
- (1996): "Referencias de tiempo en la cultura material de los castros gallegos", en HIDALGO (Coord.), 1996, 159-206.

RODRfGueZ BiempiCA, E. (1985/86): "Anclas líticas en las rías bajas gallegas", Pontevedra Arqueológica 2, 253-263.

Rodriguez CaO, C.; Xusto Rodrfguez, M., y Fariña Busto, F. (1993): A Cidade San Cibrân de Lâs, Colección Guías do Patrimonio Cultural IV, Vigo.

RODRfGUEz COLMENERO, A. (1993): "Historia del arte romano de Galicia", en F. RODRíguez IGLESLAS (Ed.), Galicia-Arte, La Coruña, 235-501.

- (Coord.) (1990): Lucus Augusti. I. El amanecer de una ciudad, La Coruña.

Rodríguez LOPEZ, C. M.; FernáNDez Rodríguez, C., y RaMil Rego, P. (1993): "El aprovechamiento del medio natural en la cultura castreña del noroeste peninsular", en Actas $1 .^{\circ}$ Congresso de Arqueologia Peninsular, I (TAE 33), Porto, 285-305.

ROMERO MASiA, A. (1976): El bábitat castreño. Asentamientos y arquitectura de los castros del NO peninsular, Santiago.

ROMERO MAStA, A., y POSE MesurA, X. M. (1986): Catalogación arqueolóxica da ría de Ferrol, La Conuña.

ROMERo MASfA, A. (1987): Castro de Borneiro. Campañas 1983-84, Arqueoloxía/Memorias 7 , Santiago.

ROMERo MASfA, A., y POSE MESURA, X. M. (1988): Galicia nos textos clásicos, La Coruña.

ROMERO MASfA, A., y ARIAS VLAS, F. (1995): Diccionario de termos de arqueoloxía e prebistoria, Vigo.

RUIZ-GÁlvEZ, M. (1982): "Nueva espada dragada en el río Ulla. Armas arrojadas a las aguas", Homenaje a A. García Alén (El Museo de Pontevedra 36), Pontevedra, 181-196.

- (1995): "El noroeste de la Península Ibérica en el contexto de la prehistoria reciente de Europa occidental", Actas 22 CNA. Vigo 1993, I, Vigo, 11-16.

SÁNCHEZ-PALENCIA, F. J., y PÉREZ, L. C. (1989); Los yacimientos auriferos de la península ibérica, en AA.VV., 1989, 16-23.

SÁNChEZ-PALENCIA, F. J., y Perea CAVEDA, A. (1995): Arqueología del oro astut. Orfebrería $y$ mineria, Oviedo.

SANTOS YANGUAS, N. (1988): El ejército y la romanización de Galicia, Oviedo.

SENÉN LOPEZ, F. (1983): "A problemática de arqueoloxía sobacuatica en Galicia): os xacementos e os materiais", II Seminario de Arqueologia del Noroeste. Santiago 1980, Madrid, 273-290.

SENIN FERNÁNDEZ, I. J. (1995): A investigación do paleolitico en Galicia. Revisión bibliogräfica, Sada (Conĩa) 1995.

SilvA, A. C. F. DA (1986): A cultura castreja no noroeste de Portugal, Paços de Ferreira.

- (1990): "A idade do ferro em Portugal", en ALARÇAO (Coord.), 1990, 257-341.

SOEIRO, T. (1984): Monte Mozinbo, Pena Fiel. 
SuÁrez Otero, J., y FariÑa Busto, F. (1990): "A Lanzada (Sanxenxo, Pontevedra), definición e interpretación de un yacimiento castreño atípico", $M D A I(M)$ 31, 309-337.

TABOADA CHIVTE, J. (1973): "La romanización del hábitat castreño", TAE 22, 237-247.

TOVAR, A. (1983): "Etnia y lengua en la Galicia antigua): el problema del celtismo", en PEREIRA (Ed.), 1983, 247-283.

TRANOY, A. (1981): La Galicie romaine. Recherches sur le nord-ouest de la péninsule ibérique dans l'Antiquité, Paris.

- (1988): "Du heros au chef. L'image du guerrier dans les sociétés indigènes du NordOuest de la Péninsule Iberique (Ile. siècle avant J.-C.-Ier. siècle après J.-C.)", Actes du Colloque <<Le monde des images en Gaule et dans les provinces voisines $\gg$, Sévres, 16 et 17 may 1987 (Caesarodunum 23), 219-227.

UNIERMANN, J. (1993): "Anotaciones al estudio de las lenguas prerromanas del noroeste de la península Ibérica", en AA.VV., 1993, 367-397

VÁZQUEZ VARELA, J. M. (1975a): "Estudio de la fauna marina de los concheros de los castros de A Peneda y Montealegre (Pontevedra)", Gallaecia 1, 141-146.

- (1975b): "El conchero del castro de Queiruga (La Coruña)", Seminario de Estudios de Arte y Arqueología 40/41, 500-503.

- (1982): "Arte prehistórico", en AA.VV., Historia del arte gallego, Madrid, 1-52.

- (1983a): "La territorialidad en la cultura castreña): una primera aproximación metodológica", en II Seminario de Arqueologia del Noroeste Peninsular. Santiago de Compostela 1980, Madrid, 95-102.

- (1983b): "La alimentación y la cocina en la cultura castreña de Galicia", Studia Zamorensia 4, 391-398.

- (1991): "Los testimonios económicos", capít. sobre el mundo castreño en AA.VV., Galicia-Historia, Santiago, 315-325.

VÁZqueZ VARELA, J. M., y BERMEjo, J. C. (1991): "La cultura castreña", en A.A.V.V., Historia de Galicia 1): de la prebistoria a la alta edad media, Vigo, 81-100.

- (1993): "Arte prehistórico", en Rodríguez IGLeSIAS, F. (Ed.), Galicia-Arte, IX, La Coruña, 173-233.

VÁzQUez VARELA, J. M.; REY, J., y CAMINo, M. (1993): "La pesca en el mundo castreño y romano de Galicia", en AA.VV., 1993, 91-100.

VÁZqueZ VARELA, J. M.; URGORRI, V., y TronCOSO, J. S. (1993): "El marisqueo en la cultura castreña de Galicia", en AA.VV., 1993, 101-112.

VÁZqueZ VARELA, J. M. (1993/94): "El cultivo del mijo, (Panicum Miliaceum, L.), en la cultura castreña del noroeste de la península Ibérica", CEG 41, 65-73.

VחIAR, F. (1995): Estudios de celtibérico y de toponimia prerromana, Salamanca. 
VILLAR, F., y ENCARNAÇAO, J. D. (Ed.) (1996): La Hispania prerromana. Actas del V coloquio sobre lenguas y culturas prerromanas de la peninsula Ibérica. (Coimbra 1994), Salamanca.

WILL, E. (1985): "Pour une "anthropologie coloniale" du monde hellénistique", en The craft of the ancient bistorian. Essays in honor of Chester G. Starr, Nueva York-Londres, 273-301.

XUSTO RODRfGUEZ, M. (1988/89): "Area de visión, topografia e territorialidade): o mundo dos castros", Boletin Auriense 18/19, 23-30.

- (1993): Territorialidade castrexa e galaico-romana na Galicia sudoriental): a Terra de Viana do Bolo, Boletin Auriense, anexo 18, Orense.

ZARZAiEjos PRIETO, M. M. (1991): "Aproximación al panorama historiográfico de la cultura castreña en la provincia de Orense (y II)", CuPAUAM 18, 189-210. 